\title{
Acoustic, Visual and Spatial Indicators for the Description of the Soundscape of Waterfront Areas with and without Road Traffic Flow
}

\author{
Virginia Puyana Romero ${ }^{1, *}$, Luigi Maffei ${ }^{1}$, Giovanni Brambilla ${ }^{2}$ and Giuseppe Ciaburro ${ }^{1}$ \\ 1 Department of Architecture and Industrial Design, Seconda Università Degli Studi di Napoli, \\ Via San Lorenzo, Abazia di San Lorenzo, Aversa 81031, Italy; luigi.maffei@unina2.it (L.M.); \\ giuseppe.ciaburro@unina2.it (G.C.) \\ 2 National Research Council of Italy, Institute of Acoustics and Sensors "O. M. Corbino", \\ Via del Fosso del Cavaliere, 100, Roma 00133, Italy; giovanni.brambilla@idasc.cnr.it \\ * Correspondence: virginia.puyana@unina2.it; Tel.: +39-3240903917
}

Academic Editor: Paul Tchounwou

Received: 12 May 2016; Accepted: 25 August 2016; Published: 21 September 2016

\begin{abstract}
High flows of road traffic noise in urban agglomerations can negatively affect the livability of squares and parks located at the neighborhood, district and city levels, therefore pushing anyone who wants to enjoy calmer, quieter areas to move to non-urban parks. Due to the distances between these areas, it is not possible to go as regularly as would be necessary to satisfy any needs. Even if cities are densely populated, the presence of a sea or riverfront offers the possibility of large restorative places, or at least with potential features for being the natural core of an urban nucleus after a renewal intervention. This study evaluates the soundscape of the Naples waterfront, presenting an overview of the most significant visual, acoustic and spatial factors related to the pedestrian areas, as well as areas open to road traffic and others where the road traffic is limited. The factors were chosen with feature selection methods and artificial neural networks. The results show how certain factors, such as the perimeter between the water and promenade, the visibility of the sea or the density of green areas, can affect the perception of the soundscape quality in the areas with road traffic. In the pedestrian areas, acoustic factors, such as loudness or the A-weighted sound level exceeded for 10\% of the measurement duration (LA10), influence the perceived quality of the soundscape.
\end{abstract}

Keywords: waterfront; calm area; soundscape; neural network; traffic noise

\section{Introduction}

National and international legislations consider road traffic noise as a major environmental problem of modern-day society [1]. Multiple control measures have been suggested to reduce it and, consequently, increase the quality of life of residents, such as "land use planning, engineering systems for traffic, traffic planning and abatement by sound insulation measures and noise control at sources" [2]. Further actions considered by European legislation for "preventing or reducing of environmental noise levels that may negatively affect human health" [2], include the addition or adjustment of quiet areas in the agglomerations. Regarding the definition of the European Noise Directive (END), "A quiet area in an agglomeration shall mean an area, delimited by a competent authority, for instance, which is not exposed to an A-weighted equivalent sound pressure level (measured over the $24 \mathrm{~h}$ period, with a $10 \mathrm{~dB}$ penalty added to the levels between 23:00 and 07:00 $\mathrm{h}$ and a $5 \mathrm{~dB}$ penalty added to the levels between 19:00 and 23:00 h), representative over one year (Lden) or another appropriate noise indicator greater than a certain value set by the Member State, from any noise source" [3]. However, the guidelines of "Good Practice in Quiet Areas" highlight that noise levels cannot be the only parameter for characterizing a quiet area, and that "an area where noise is 
absent or at least not dominant" would be a better definition. It also remarks that "the designation 'calm area' or 'tranquil area' would fit more closely to what the public experiences" [1].

In recent years, the structure and type of use of urban waterfronts has changed substantially, with it generally being due to their intensive use in various fields, such as residential, leisure or sport. This has often led to abusive practices during periods of economic growth and abandonment of entire areas during negative ones. The regeneration of these areas is associated not only to an urban improvement of empty, decommissioned or abandoned places but also to collective social, political, environmental or legislative demands. The competent authorities should make an effort to either promote existing calm areas or adapt new ones within or near urban centers in order to facilitate the frequent and full enjoyment of their benefits. In cities with a waterfront, this wide open space offers multiple possibilities for the design and implementation of restorative areas that can improve the quality of life of people in general.

However, the positive effects associated to waterfronts can be cancelled by the vehicular traffic that runs through the adjacent streets. The perceptual differences between waterfront areas with and without road traffic were pointed out in the users' "appraisals of the soundscape quality" in a previous study [4].

As stated by ISO 12913-1 [5], the soundscape appraisal is affected not only by the sound, but also by the context in which the individual is immersed. Although the perception of noise depends on the physical properties of sound, such as amplitude and frequencies, several studies support the idea established by ISO and defend that the visual factors may, in general, also influence the perception of noise and its evaluation (e.g., [6-9]). In particular, they may affect the perception of the traffic noise and other sound sources significantly [10,11], especially in areas with water as a predominant visual element [12]. In order to evaluate the soundscape assessment, several studies have considered mathematical models (e.g., linear regression, ordinal regression or artificial neural networks) to characterize its acoustic features (e.g., [13-15]).

The aim of this study was to compare the visual, acoustic and spatial factors that may affect the soundscape perception of three types of areas (area with limited road traffic, areas open to road traffic and pedestrian area). A mixed methodology based on artificial neural networks was used. The seafront of Naples was chosen as a case study, since this area has a high potential to be converted into the healthy core of the city.

\section{Characterization of Outdoor Urban Sound}

Acousticians have primarily relied on so-called acoustic indicators to characterize outdoor urban sounds. A wide variety of indicators has been used, ranging from simple verbal ones that express the feelings of the subjective characteristics of the sounds, to more complex indicators based on field measurements. Some of these indicators are percentiles, defined as the A-weighted sound pressure levels exceeded " $n$ " $\%$ of a time interval (LAn). The most frequently used indicators are the A-weighted equivalent sound pressure level in $\mathrm{ABA}$, measured over a period of time $\mathrm{T}$ (LAeq,T), the background levels (LA90 or LA95), and descriptors expressing the variance of the sound spectrum [16]. However, there is agreement that a single approach cannot be appropriate when evaluating the perception of the sound quality and annoyance produced by noise.

On the basis of the validity of statistical levels, the range of LA50 and LA95 has been proven to predict the perception of quietness better than conventional LAeq or LA10 [13,14]. Similarly the indicators LA10, LA50 and LA95 were chosen as predictors of the "good quality" of the soundscape in parks [17]. However, it is still not clear which indicators are the most appropriate for characterizing the sound quality of urban areas and, more specifically, the soundscape of waterfronts.

In recent years, a great deal of soundscape research has focused on the influence of visual factors. Current literature on audio-visual interactions has shown that visual factors can influence the loudness perception of traffic noise (e.g., [9,18-20]). The influence of the motion on the perception of traffic noise was tested in an experiment in which a video of a moving car was displayed, obtaining the result 
that the participants' assessments on noise were influenced not only by the sonic stimulus but also by the visual stimulus [21]. Colors have been also considered on the loudness and noise annoyance perception caused by traffic noise; the effect on the loudness perception of images of differently colored sports cars displayed simultaneously to car sounds [22,23], the influence of color and brightness on the assessment of the traffic noise annoyance through colored images [24], or the visualization of indoor scenes [25] are several significant examples. Other studies have considered factors related to the visual components and the spatial relationship between the different elements that make up an environment (e.g., $[8,26-28])$.

As previously mentioned, acoustic and visual parameters can affect the sonic perception in different urban open spaces. The relationship between these parameters and the soundscape can be defined through several mathematical models. Logistic regressions models have been used to study the association between the objective acoustic parameters of different urban environments and the appraisals on the soundscape [29]. Linear regression models have been also developed to evaluate specific case studies in urban open spaces using different subjective parameters, such as verbal descriptors or generic quality factors (e.g., cleanliness, expectation), showing a good correlation with the soundscape (e.g., $[4,30])$. Additional studies have focused on the categorization of outdoor soundscapes, using statistical techniques, such as "fuzzy ant" models. The applicability of the fuzzy concept has been proved in the analysis of ordinal appraisal responses (e.g., "a little", "quite a bit", "a lot"), that are difficult to be quantified numerically [31,32]. Other studies have used artificial neural networks to characterize the soundscape [15], predict urban noise [33] as well as elaborate soundscape quality maps [34]. Their performance has been proved to be generally better than traditional methods such as linear regression (e.g., [15,33]).

\section{Materials and Methods}

\subsection{Area of Study}

Naples is an example of an overcrowded city with a reduced number of open spaces: the waterfront being of the few exceptions. The general interest in providing calm areas is shown in some of the initiatives undertaken by citizens and private professional organizations to improve the quality of certain zones of the city, including the seafront, through urban renewal proposal competitions [35]. The authorities are also aware of the problem and are implementing some actions, including pedestrianizing several streets.

The study was carried out along the stretch of the Naples waterfront between "Mergellina" and "Ferdinando Acton". The different places were grouped according to three conditions of road traffic flows; pedestrian, open to road traffic and limited traffic areas (see Figure 1).

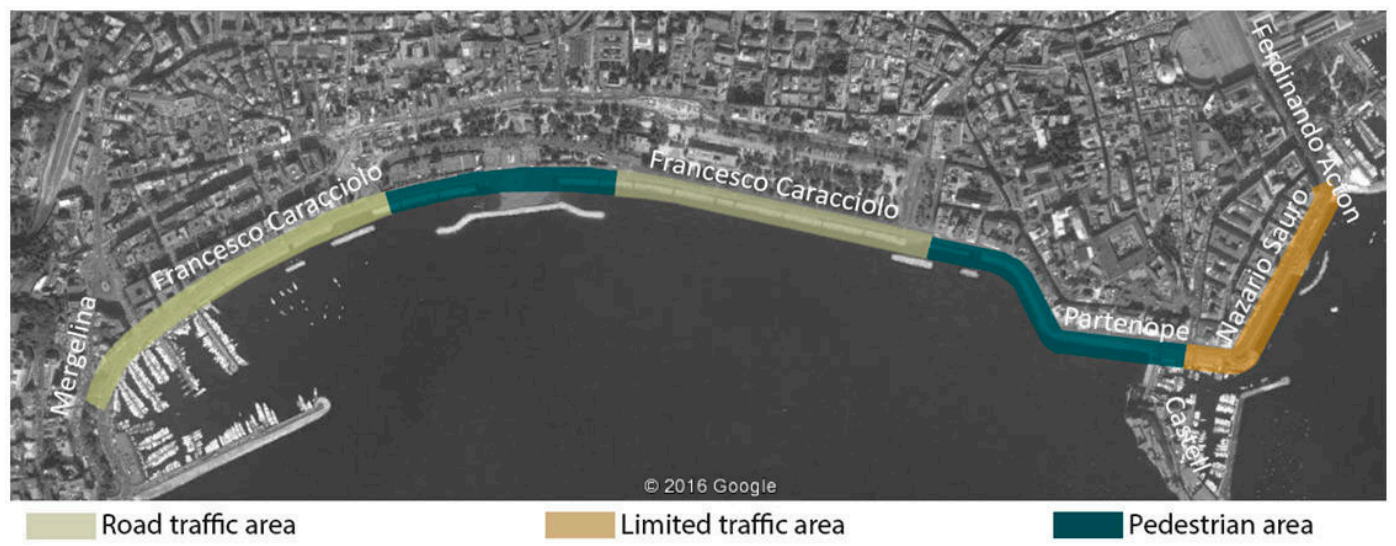

Figure 1. Stretch of the waterfront under investigation (base aerial photograph @ 2016 Google). 


\subsection{Materials}

Acoustic, visual and perceptual data, collected during two field surveys conducted in winter and summer 2014 along the Naples seafront (see areas under study in Figure 2), were used. Face to face interviews were carried out on weekdays and weekends from 10:00 h to 17:00 h. The three groups of areas have a homogeneous distribution of participants, from a total of 254 randomly selected interviewees (limited traffic areas: $33 \%$, open to road traffic areas; $24 \%$, pedestrian areas: $41.3 \%$ ). Among them, $27.7 \%$ were tourists (34.6\% from South Italy, 36.5\% from North Italy and from other countries: South Europe 9.6\%, North Europe 17.3\%, South America 1.9\%). Age, gender and occupation were distributed in the sample as shown in Table 1. More information on the methodology and data acquired can be found in $[4,36]$. All the data used in this study comes from on-site interviews and the post processing of sound recordings, $360^{\circ}$ photographs and aerial photographs.
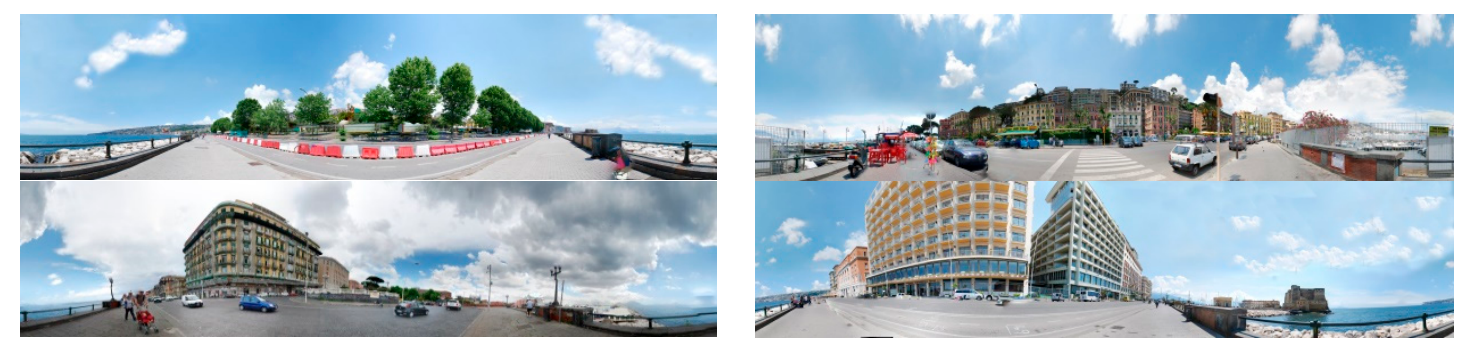

Figure 2. Examples of the panoramic photographs from which the class percentages were calculated.

Table 1. Characteristics of the population sample.

\begin{tabular}{ccccc}
\hline Characteristic & Value & Limited Traffic (\%) & Road Traffic (\%) & Pedestrian (\%) \\
\hline \multirow{2}{*}{ Gender } & Male & 51.2 & 51.7 & 53.0 \\
& Female & 48.8 & 48.2 & 49.4 \\
\hline \multirow{5}{*}{ Age } & $18-24$ & 28.0 & 32.9 & 27.7 \\
& $25-29$ & 22.1 & 15.3 & 13.3 \\
& $30-39$ & 28.0 & 23.5 & 33.7 \\
& $40-49$ & 9.3 & 9.4 & 16.9 \\
& $50-59$ & 5.8 & 12.9 & 7.2 \\
& $\geq 60$ & 7.0 & 5.9 & 1.2 \\
\hline \multirow{5}{*}{ Occupation } & Student & 2.3 & 32.9 & 31.3 \\
& Housewife & 3.5 & 12.9 & 10.8 \\
& Retired & 32.6 & 3.5 & 1.2 \\
& Employed & 22.1 & 18.8 & 30.1 \\
& Self-employed/freelance & 7.0 & 5.9 & 21.7 \\
& Unemployed & & & 4.8 \\
\hline
\end{tabular}

Among the data from the surveys, the subjective appraisals on the soundscape quality and objective acoustic parameters namely equivalent sound pressure level (Leq), A-weighted equivalent sound pressure level (LAeq), percentiles LA5, LA10, LA50, LA90, LA95, Loudness (N5), Sharpness (S), Roughness (R) and Fluctuation Strength (F) were used.

In order to evaluate the visual influence on the soundscape quality perception, spatial metrics (calculated from the aerial photographs by the software Fragstats (University of Massachusetts, Amherst) $[37,38]$, as well as the percentages of the landscape elements that can be seen in situ (calculated from the $360^{\circ}$ photographs by the image editing software Perfect Effects (OnOne Software, Portland, OR, USA) were obtained. Spatial metrics are objective indicators of the spatial and visual variability of the different landscape uses defined along the areas under study, with them having been widely used in urbanism $[39,40]$ and more recently also in acoustics to evaluate the soundscape of urban $[8,27,41]$ and rural areas [42]. 
The spatial metrics considered in this study were the "percentage of landscape" (PLAND), "large patch index" (LPI), "contiguity" (CONTIG_MN), "shape" (SHAPE_MN), "proximity" (PROX_MN), "connect" (CONNECT), "normalized landscape shape" (NLSI) and "split" (SPLIT).

PLAND is one of the most important measurements of landscape composition, and indicates which part of the landscape is comprised by a particular use. The LPI is another measurement of the landscape composition that refers to the percentage of a landscape use comprised by the largest patch $[37,38]$. CONTIG and SHAPE are shape metrics that describe the complexity of the geometry of the landscape use. The isolation metrics PROX and CONNECT describe the relationship with the spatial context of the individual patches [37,43]. SPLIT and NLSI are measurements that give an idea of the aggregation or division of the patches. The formulas and detailed meanings of the spatial metrics used in this paper are in the documentation of the Fragstats software [37,38]. Ten land uses were defined, namely sea, garden, tree, fountain, generic building, singular building, food services, construction site, pedestrian path and vehicles path. According to the criteria of various studies on the sonic environment that used spatial metrics $[8,27,41,42]$, the variables have been calculated within an area with $175 \mathrm{~m}$ radius. From now on, the spatial variables will be cited in the text as the name of the spatial metric followed by the land use, i.e., PLAND_Pedestrian_path will stand for percentage of landscape metric calculated for the land use "pedestrian path", PROX_Sea will stand for proximity metric calculated for the land use "sea".

The "class percentages in the panoramic photographs" (CP), i.e., sky (CP_Sky), sea (CP_Sea), vegetation (CP_Vegetation), generic buildings (within three distances "less than $100 \mathrm{~m}$ ", "100-175 m" and "beyond $175 \mathrm{~m}$ "), singular buildings (CP_Singular), food services activities (CP_Food services), pedestrian paths (CP_Pedestrian path) and vehicles paths (CP_Vehicles path) were also calculated (see Figure 2).

\subsection{Methods}

Statistical analysis was performed to compare the three types of areas under study, as well as to define the most relevant acoustic and visual factors that may influence the soundscape perception (among the evaluated ones). The factors obtained can give an idea of the weak points / potentialities of these areas in order to improve their soundscape quality and, subsequently, their livability. The comparison was carried out using a methodology based on the "minimum redundancy and maximum relevance features selection method" (mRMR), "artificial neural networks" (ANN) and the "relative importance of the variables" [39]. The analysis was performed using the open-source software, R [44]. To reduce the large number of variables, the mRMR method was applied to each group of areas. Subsequently, three artificial neural networks were proposed with the selected input variables. The relative importance of each variable [45] was evaluated for the three models obtained so as to take into account the acoustic and visual singularities of the places.

\section{Results}

\subsection{Statistical Analysis}

The nature of the perceived sound sources plays an important role on the positive or negative appraisal of the soundscape. To study the responses on the soundscape quality, the sound sources heard, and recognized as predominant, were analysed. Figures 3 and 4 report the percentage of people that perceived a certain sound source in each type of area and the percentage of the most perceived sound sources, respectively. 


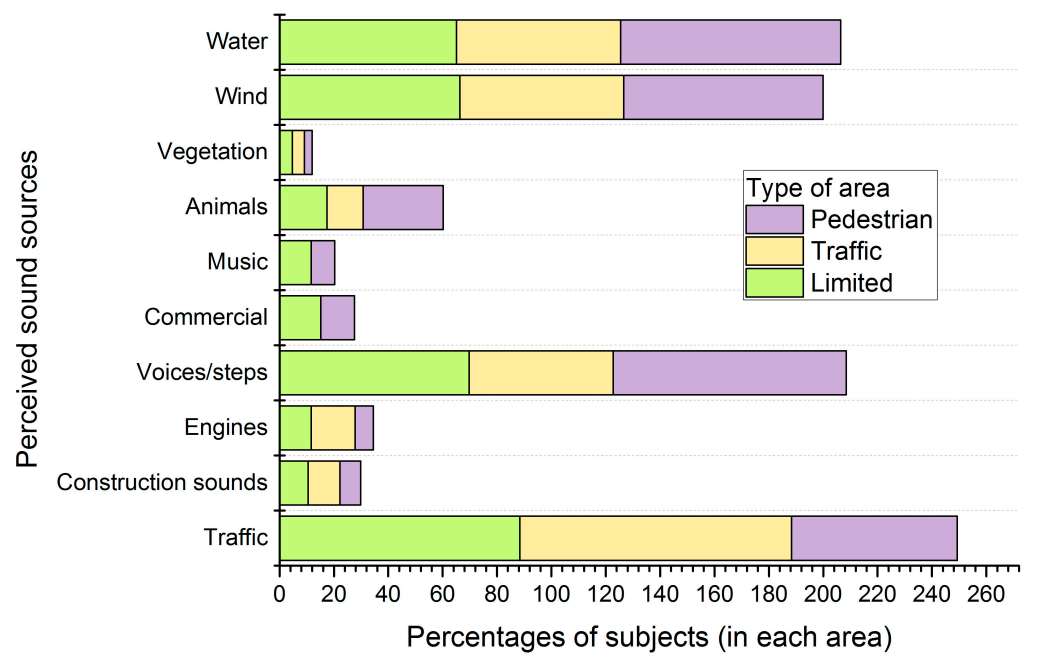

Figure 3. Percentage of subjects that recognized a certain sound source within the three types of areas a priori classified as pedestrian areas, open to road traffic areas and limited traffic areas.

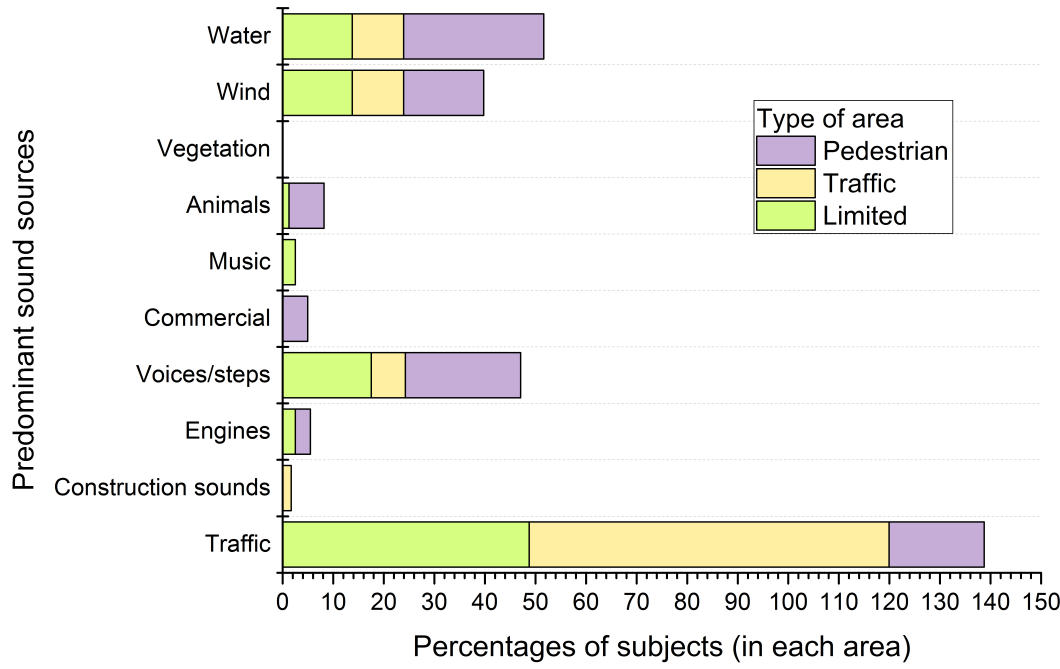

Figure 4. Percentage of subjects that recognized a certain sound source as the predominant one within the three types of areas a priori classified as pedestrian areas, open to road traffic areas and limited traffic areas.

The predominant sound source recognized by the interviewees is different between the three types of areas under study (see Figure 4). While a high number of people recognize the traffic as the predominant source in the road traffic $(71.2 \%)$ and limited areas $(48.7 \%)$, in the pedestrian areas, the predominant sound source is the water, with a smaller percentage $(27.7 \%)$ compared to the percentage of the predominant sound source in other areas. Water is also recognized as predominant by a high percentage of subjects in the open to road traffic areas.

Voices and steps were chosen as predominant by a higher percentage of subjects in the pedestrian and limited areas $(22.7 \%$ and $17.5 \%$, respectively) than in the road traffic areas $(6.8 \%)$.

The acoustic, spatial and visual parameters were analysed in comparison with the appraisals on the soundscape quality in the three groups (see Figure 5, Tables 2 and 3). The pedestrian areas are the ones with more positive appraisals of the soundscape quality, with a median value of 5 , and a mean value of 5.2 (see Figure 5). This group has the smallest range of answers, with scores from 2 to 7 that also indicate less negative scores. The road traffic areas have a negative median value (3) and mean score (3.3), being, as expected, the group with the worst appraisals. Most of the appraisals on the 
soundscape quality of this group are between 2 and 5 (first and third quartile), being the group with the most spread answers. The mean levels of LAeq are quite high even in the pedestrian areas. This is due to the dense and loud anthropogenic activities at the Naples waterfront.

Analysis of the panoramic photograph parameters shows that the percentages of each category among the three types of areas are within a small range of values (Table 2). The CP_Sky is the most present element in the panoramic photographs, with a percentage higher than $50 \%$ in all the groups. It is followed by the percentages of buildings (CP_Building 100), areas with traffic (CP_Traffic), and pedestrian areas (CP_Pedestrian_path). The road traffic areas are the ones with the lowest percentage of buildings in a distance of $100 \mathrm{~m}$ (CP_Building 100) due to being near (in two of the three road traffic sites) green areas.

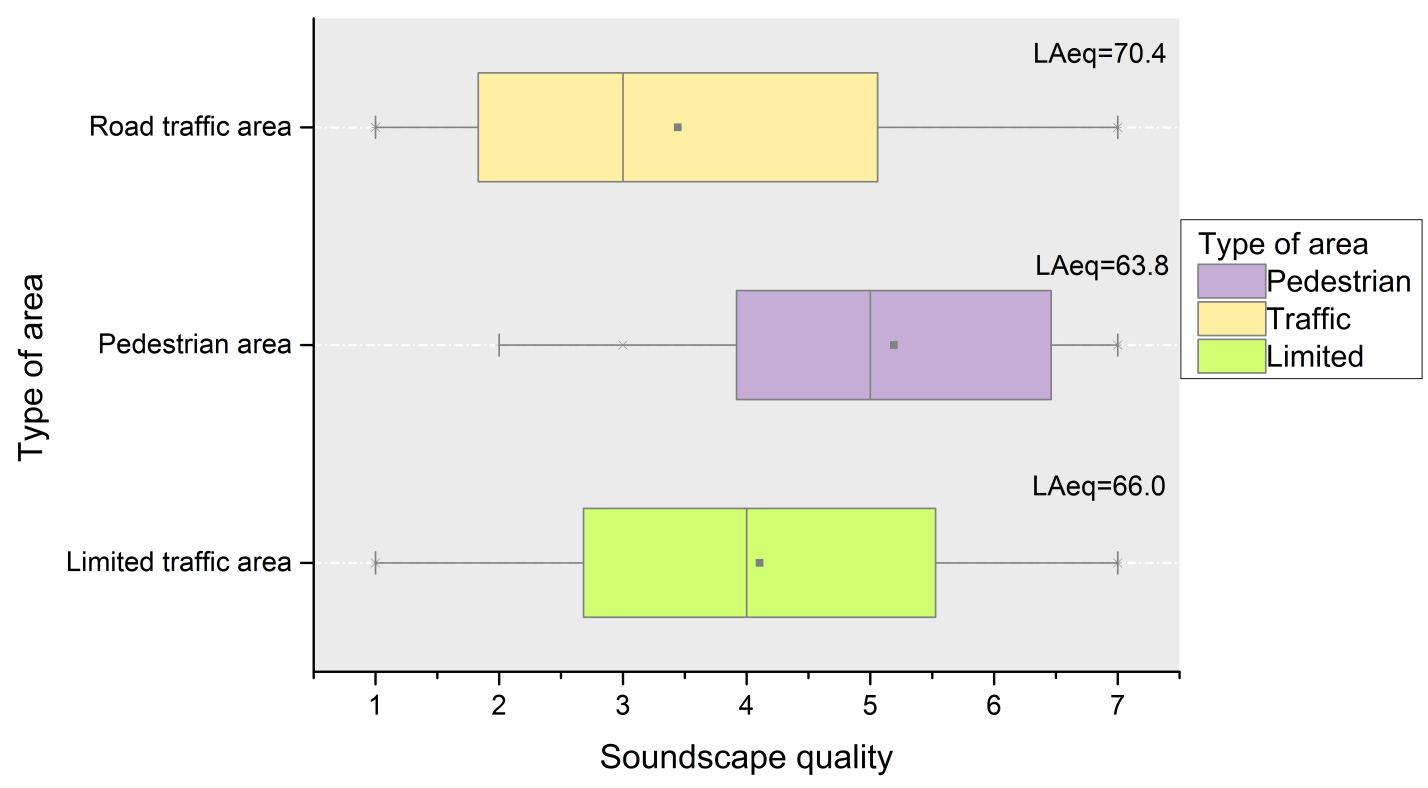

Figure 5. Boxplot of the appraisals of the soundscape quality, (rated in a 7 points Likert scale from 1 (very low) till 7 (excellent)), in the three types of areas a priori classified as pedestrian areas, open to road traffic areas and limited traffic areas (bottom horizontal axis).

Table 2. Mean values of the percentages in the panoramic photographs (CP) of all the classes in the three types of area.

\begin{tabular}{cccc}
\hline \multirow{2}{*}{ CP_Class } & \multicolumn{3}{c}{ Area } \\
\cline { 2 - 4 } & Limited Traffic & Pedestrian & Road Traffic \\
\hline CP_Sky & 54.9 & 55.1 & 51.4 \\
CP_Sea & 3.1 & 2.7 & 2.3 \\
CP_Pedestrian_path & 8.0 & 11.6 & 8.6 \\
CP_Vehicles_path & 9.1 & 4.8 & 9.7 \\
CP_Singular & 0.9 & 0.8 & 0.2 \\
CP_Building > 175 & 0.5 & 0.6 & 0.7 \\
CP_Building 100-175 & 0.9 & 1.1 & 0.5 \\
CP_Building 100 & 15.6 & 14.0 & 7.1 \\
CP_Vegetation & 1.4 & 1.1 & 9.7 \\
CP_Food_services & 0.0 & 0.1 & 0.2 \\
\hline
\end{tabular}

$\mathrm{CP}$ of the classes "sky" (CP_Sky), "sea" (CP_Sea), "pedestrian paths" (CP_Pedestrian path), "vehicles path" (CP_Vehicles path), "singular buildings" (CP_Singular), generic buildings within three distances: "less than 100 m" (CP_Building 100), "100-175 m" (CP_Building 100-175) and "beyond 175 m" (CP_Building > 175), "vegetation" (CP_Vegetation) and "food services" (CP_Food services).

Table 3 shows the mean values of the PLAND. PLAND_Sea is the spatial metric with the highest percentage of landscape compared with the rest of the land uses. The second and third metrics 
with high percentages are PLAND_Pedestrian_path and PLAND_Vehicles_path, respectively, and the percentages vary considerably in areas with and without traffic. The reason why the areas with traffic have a high metric PLAND_Pedestrian_path value is again due to the nearby park "Villa Comunale", since the paths between the gardens are considered as pedestrian. The fourth is the percentage of buildings within a distance of $175 \mathrm{~m}$ of the interviewee. As in the previous plot, the (PLAND_Building) is lower in the road traffic areas than in the other types.

Table 3. Mean values of the spatial metric percentage of landscape (PLAND) of all the land uses in the three types of area.

\begin{tabular}{cccc}
\hline \multirow{2}{*}{ PLAND_Land Use } & \multicolumn{3}{c}{ Area } \\
\cline { 2 - 4 } & Limited Traffic & Pedestrian & Road Traffic \\
\hline PLAND_Building & 14.9 & 14.1 & 6.1 \\
PLAND_Singular & 0.1 & 0.6 & 0.0 \\
PLAND_Food_services & 2.5 & 4.1 & 0.6 \\
PLAND_Sea & 42.0 & 38.3 & 32.8 \\
PLAND_Fountain & 0.1 & 0.0 & 0.1 \\
PLAND_Construction & 0.2 & 0.1 & 0.6 \\
PLAND_Garden & 3.8 & 3.8 & 5.0 \\
PLAND_Tree & 2.1 & 1.8 & 4.1 \\
PLAND_Pedestrian_path & 15.9 & 17.3 & 21.1 \\
PLAND_Vehicles_path & 12.9 & 14.3 & 9.2 \\
\hline
\end{tabular}

PLAND of the land uses "generic buildings" (PLAND_Building), "singular buildings" (PLAND_Singular), "food services" (PLAND_Food_services), "sea" (PLAND_Sea), "fountain" (PLAND_Fountain), "construction sites" (PLAND_Construction), "gardens" (PLAND_Garden), "trees" (PLAND_Trees), "pedestrian paths" (PLAND_Pedestrian path) and "vehicles paths" (PLAND_Vehicles path).

\section{2. $m R M R, A N N$ and Relative Importance of the Variables}

The mRMR selection method was applied to 91 variables resulting from all the acoustic parameters, spatial metrics and percentages of the visual elements contained in the panoramic photographs.

The mRMR method avoids the repeated information that can be found in models composed by highly correlated variables. Another advantage of the mRMR method is that it avoids a subjective selection of the variables that will compose the model, providing a group of factors obtained from mathematical algorithms. The mRMR method was applied to each type of area (pedestrian, road traffic and limited traffic areas).

Neural network models were also calculated for each type. The database of each type of area was divided into train $(70 \%)$, test $(15 \%)$ and validation sets $(15 \%)$. The 10 best performing models among the 1000 computed for each type were selected. The interpretation of the relative importance of the variables $[45,46]$ was considered in the selection of the best performing models, in order to choose the ones that best explain the sonic environment of each group of areas.

Table 4 shows the correlation coefficients of the train, test and validation sets of the three calculated models. The model for the limited traffic areas is the best performing one, with a correlation coefficient of the train set of rLimited_Test $=0.96$. The test and validation sets have also very high correlation coefficients, with a rLimited_Val $=0.798$. The worst performing model is the one of the road traffic areas, with a rTraffic_Test $=0.86$. Even though the coefficient of correlation is low for the validation set, the model is still satisfactory (rTraffic_Val $=0.55$, RMSE Traffic_Val $=1.159$ ).

Table 4. Correlation coefficient and root mean square error for the train (RMSE), test and validation sets of the best performing model in each group of areas.

\begin{tabular}{ccccccc}
\hline Areas & \multicolumn{3}{c}{ Correlation Coefficient } & \multicolumn{3}{c}{ RMSE } \\
\hline Group & Train & Test & Validation & Train & Test & Validation \\
Limited & 0.960 & 0.953 & 0.798 & 0.653 & 0.720 & 1.485 \\
Traffic & 0.855 & 0.734 & 0.551 & 0.356 & 0.665 & 1.159 \\
Pedestrian & 0.872 & 0.908 & 0.705 & 0.235 & 1.117 & 1.179 \\
\hline
\end{tabular}




\subsubsection{Limited Traffic Areas}

The network topology obtained from the application of the mRMR method to the limited road traffic areas is shown in Figure 6. In order to evaluate "the probability of concordance between predicted and observed responses" [47] of the results of the mRMR, the mean concordance index $\mathrm{C}$ was calculated [48]. Values higher than 0.5 indicate the existence of a predictive discrimination power. The mean concordance index obtained among the variables selected in the limited traffic areas is $C=0.64$; then, the set of variables can be accepted.

For this group, the LAeq was the only acoustic parameter selected by the mRMR algorithm. It seems that other acoustic parameters do not add significant improvements to the information contained in the chosen set of variables. Visual parameters related to the sea, the pedestrian areas and the food services areas were also included in the selection.

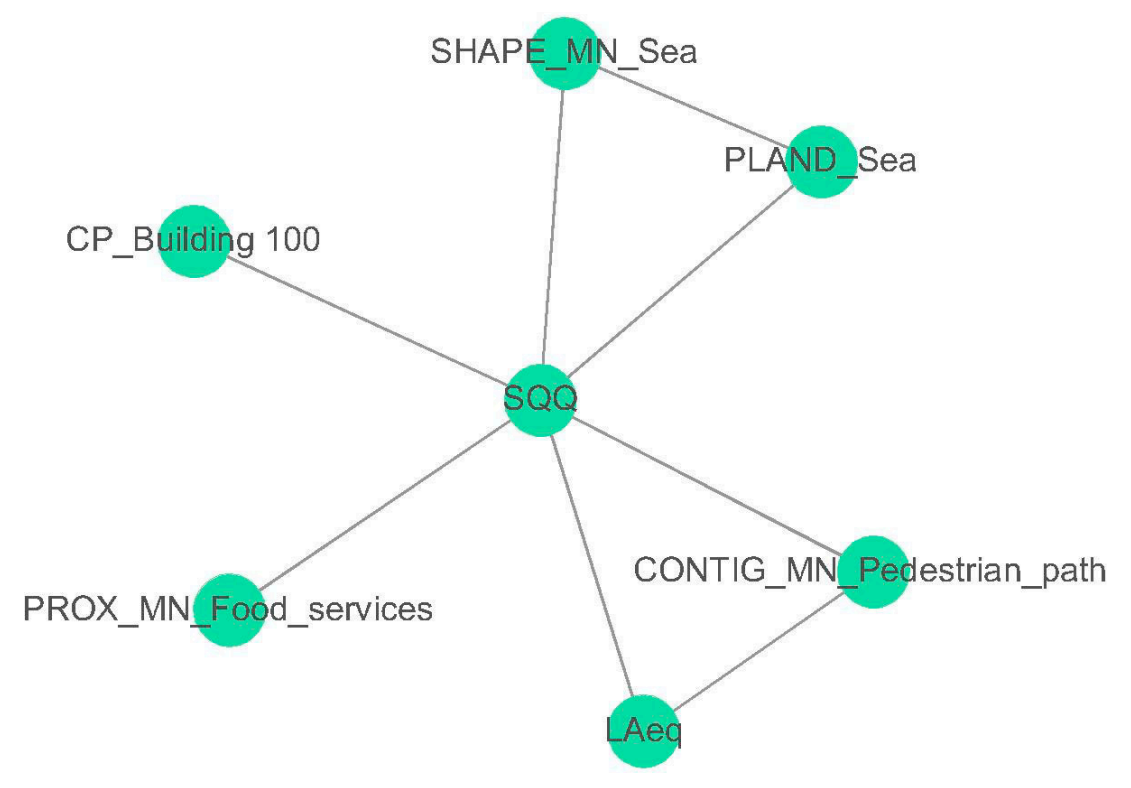

Figure 6. Inferred mRMR network topology of the soundscape quality (SQQ) for the limited road traffic areas. The variables selected were "percentage of generic buildings in the aerial photograph within a distance of 100 m" (CP_Building_100), spatial metric "proximity" calculated for the land use "food services" (PROX_MN_Food_services), spatial metric "contiguity" calculated for the land use "pedestrian path" (CONTIG_MN_Pedestrian_path), spatial metric "percentage of land use" calculated for the land use "sea" (PLAND_Sea), spatial metric "shape" calculated for the land use "sea" (SHAPE_MN_Sea) and A-weighted equivalent sound pressure level (LAeq).

Due to the morphology of the streets network, in the limited traffic areas the vehicles flow was not equal along all of "Via Nazario Sauro". It decreases near the pedestrian areas ("Castel dell'Ovo"), and increases near "Via Acton" (see Figure 2). Near the pedestrian areas, there are lower traffic noise levels, and therefore, a different perception of the soundscape quality. This could explain the selection of the spatial metric CONTIG_MN_Pedestrian. Another parameter selected by the mRMR method was SHAPE_Sea. The spatial metric SHAPE reveals how complex the shape of the perimeter of the land use is. Even if the perimeter of the sea limit with the promenade within a radius of $175 \mathrm{~m}$ can be considered quite similar, it is not so. There are places where the perimeter is not straight.

The relative importance of the variables that appear in the model of the limited road traffic areas is shown in Figure 7. The PLAND_Sea is the metric with highest influence on the soundscape perception in the areas with limited traffic (39.6\%). The area with a higher PLAND_Sea is the one nearest to the pedestrian area, in which the noise levels are lower due to the configuration of the streets network and the traffic flows. 


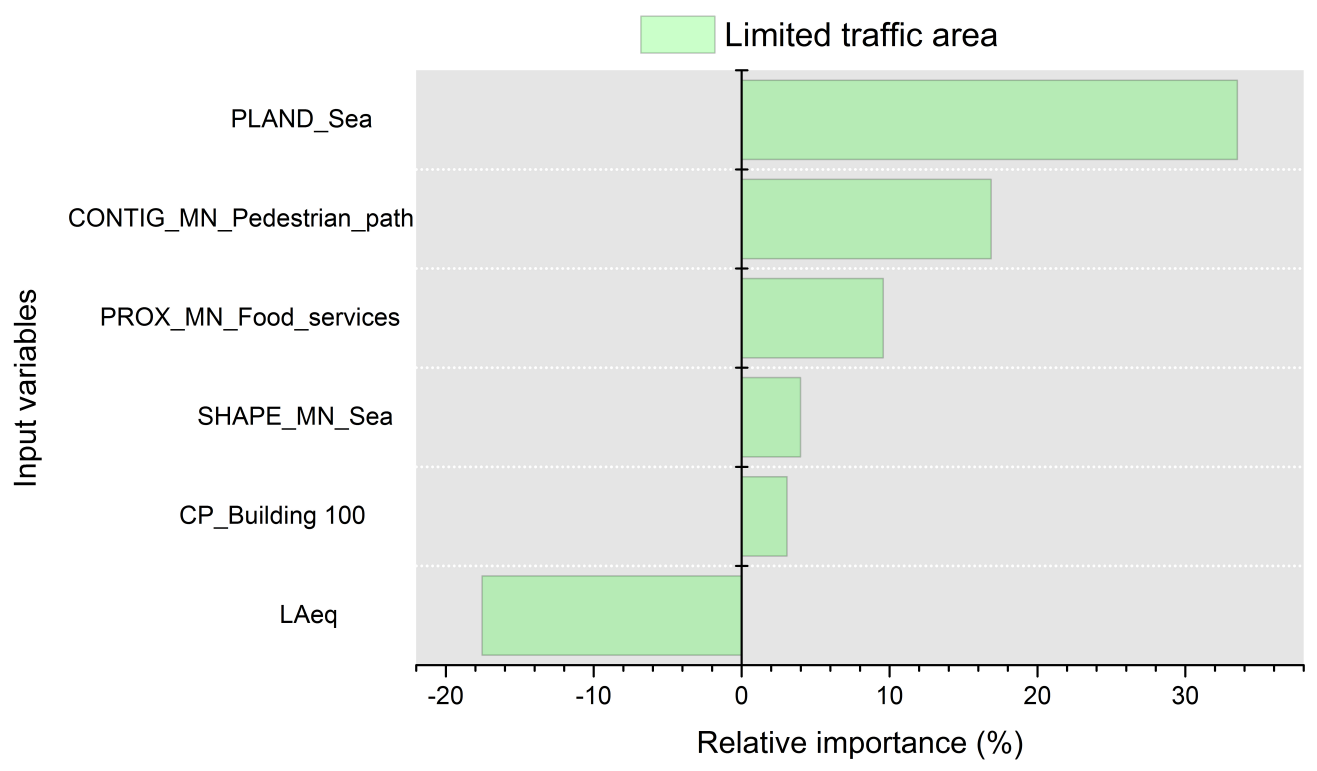

Figure 7. Percentage of relative importance of the predictors on the results calculated with the Olden et al. method for the limited traffic areas. Values higher than zero mean a positive relative effect, and lower than zero a negative relative effect. The input variables are from top to bottom spatial metric "percentage of land use" calculated for the land use "sea" (PLAND_Sea), spatial metric "contiguity" calculated for the land use "pedestrian path" (CONTIG_MN_Pedestrian_path), spatial metric "proximity" calculated for the land use "food services" (PROX_MN_Food_services), spatial metric "shape" calculated for the land use "sea" (SHAPE_MN_Sea), "percentage of generic buildings in the aerial photograph within a distance of 100 m" (CP_Building_100) and A-weighted equivalent sound pressure level (LAeq).

The SHAPE_MN_Sea has also a positive influence on the conformation of the model, and therefore, the more irregular the perimeter between the sea and promenade is (within a radius of $175 \mathrm{~m}$ ), the higher the soundscape appraisal.

The land use "pedestrian path" has higher contiguity (CONTIG_MN_Pedestrian_path) near to the pedestrian areas, and since they have less traffic noise, have more positive scores on the soundscape quality than any other parts of this land use. The only negatively correlated parameter is the LAeq, as expected. The proximity of food services areas is also a positive factor on the soundscape appraisal. Current literature reports how this kind of anthropogenic activity has either a positive or neutral influence on the sonic perception regarding the environment assessment [13,49-51]. In this case, they have a positive influence.

\subsubsection{Road Traffic Areas}

The network topology obtained from the application of the mRMR method to the road traffic areas is shown in Figure 8. The mean concordance index calculated from the variables selected in the road traffic areas is $C=0.55(C>0.5)$. Therefore, the set of variables obtained from the mRMR method can be accepted.

In the road traffic areas, the mRMR algorithm has selected only spatial metrics as visual factors (NLSI_Garden, LPI_Food, Pland_Sea and Shape_MN_Traffic), and two acoustic parameters, namely LA95 and LA50, as the only acoustic variables selected (see Figure 8).

The visual parameters selected are related to the sea, the green areas, the food services and the road traffic areas. The sea is hardly heard in the road traffic areas, only when the morphological configuration of the frontier between the waterfront promenade and the sea allows it. However, traffic noise is heard nearly all the time. Therefore, it seems reasonable that visual parameters have a positive influence on the positive appraisals of the sonic environment. 


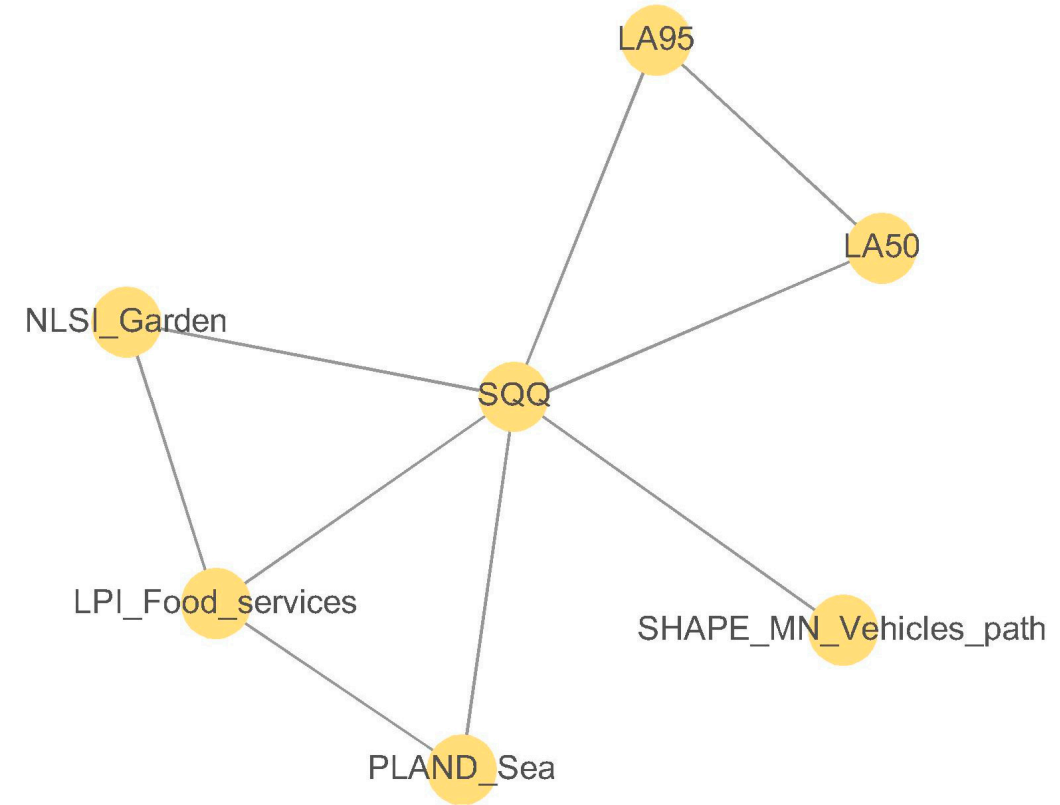

Figure 8. Inferred mRMR network topology of the soundscape quality (SQQ) for the road traffic areas. The variables selected were the spatial metric "normalized landscape shape" calculated for the land use "garden" (NLSI_Garden), spatial metric "large patch index" calculated for the land use "food service" (LPI_Food), spatial metric "percentage of land use" calculated for the land use "sea" (PLAND_Sea), spatial metric shape calculated for the land use "vehicles path" (SHAPE_MN_Vehicles_Path), A-weighted sound pressure level exceeded 50\% of time (LA50) and A-weighted sound pressure level exceeded $95 \%$ of time (LA95).

Figure 9 shows the relative importance of the variables that compose the model of the road traffic areas. The spatial metric NLSI_Garden gives an idea of the relationship between the minimum and maximum perimeter of the green areas near each subject (to whom the interview was carried out). Since the influence of the NLSI_Garden on the soundscape appraisal is positive (23.9\%), the higher the dispersion of the green areas is, the more negative the appraisal on the soundscape quality is.

The percentage of sea has also a significant positive influence on the soundscape quality appraisals. The areas near "Mergellina" have low PLAND_Sea values due to the presence of jetties and yachting port, with the assessments on the sonic environment being more negative than in the other road traffic sites. There are also visual obstacles (small metallic or wooden constructions and billboards and metallic fences) that do not allow a proper vision of the sea. Thus, the results confirm the positive relationship between the vision of the sea and the soundscape quality.

As expected, higher levels of background noise (LA95) lead to a negative appraisal of the sonic environment. The same trend is observed for LA50.

The spatial metric SHAPE_MN_Vehicles_path is negatively related to the soundscape quality appraisal. This metric depends on the perimeter and the square root area; therefore, the more irregular and complex the shape of the street network is, the lower the values of the soundscape quality are. This fact is confirmed in the places with road intersections (near "Mergellina") with more negative appraisals than the area near the "Villa Comunale" park, which is mainly straight. There is a mean difference of $3 \mathrm{~dB}$ in both areas, so other acoustic factors associated to the intersections include tyre noise.

In the road traffic areas, the food services present include kiosks and a bar near the intersection of "Via Mergellina". The LPI metric relates the surface of the total area (around the interviewee) to the surface of the largest element of a specific land use. Since they have a positive relationship with the soundscape, this may mean that the large food services areas (bars and restaurants) have a more positive relationship with the soundscape appraisal than the smaller ones (small kiosks). 


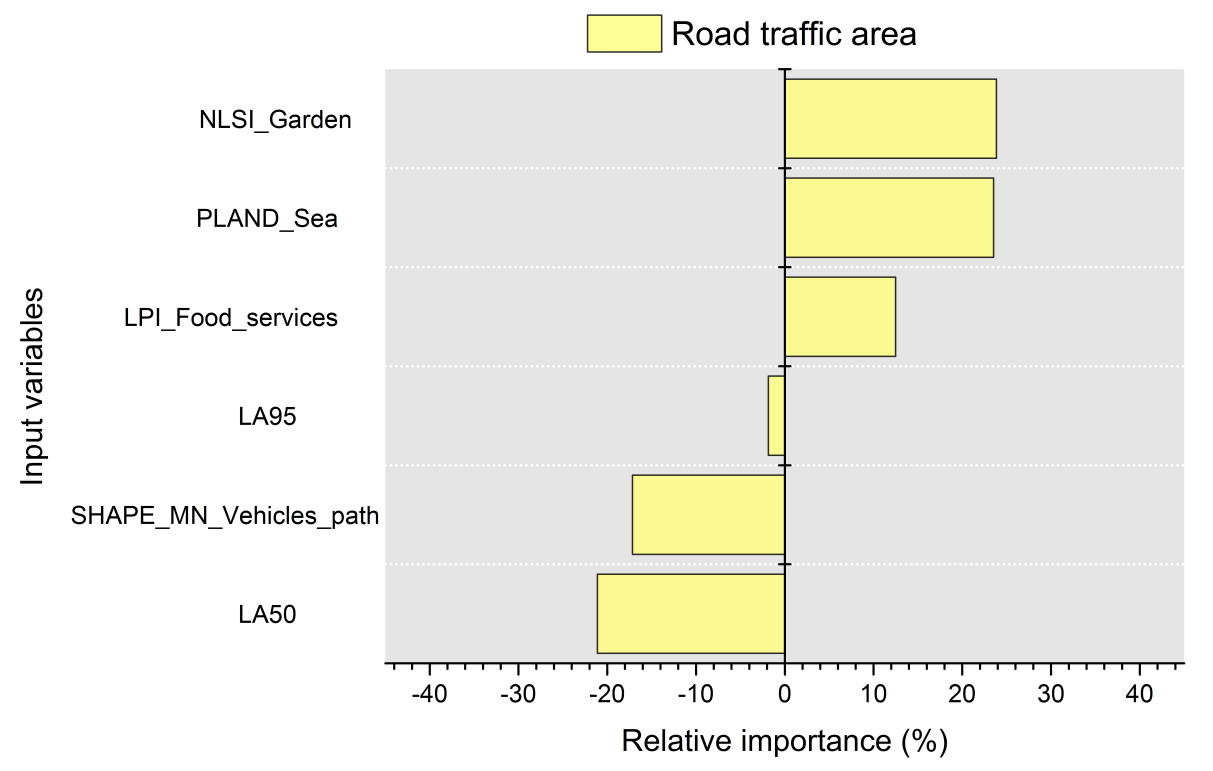

Figure 9. Percentage of relative importance of the predictors on the results calculated with the Olden et al. method for the road traffic areas. Values higher than zero mean a positive relative effect, and lower than zero, a negative relative effect. The input variables are from top to bottom spatial metric "normalized landscape shape" calculated for the land use "garden" (NLSI_Garden), spatial metric "percentage of land use" calculated for the land use "sea" (PLAND_Sea), spatial metric "large patch index" calculated for the land use "food service" (LPI_Food), A-weighted sound pressure level exceeded 95\% of time (LA95), spatial metric shape calculated for the land use "vehicles path" (SHAPE_MN_Vehicles_Path) and A-weighted sound pressure level exceeded 50\% of time (LA50).

\subsubsection{Pedestrian Areas}

Figure 10 shows the variables selected by the mRMR method for the pedestrian areas. The mean concordance index calculated from the variables selected in the pedestrian areas is $C=0.56(C>0.5)$. Therefore, the set of variables selected can be accepted.

Five acoustic parameters were selected in the pedestrian areas, namely LAeq, R, LA50, LA10 and N5. The visual parameters selected are related to the buildings within a radius of $100 \mathrm{~m}$ (from the panoramic photo), the food services (PROX_MN_Food) and the singular buildings (SPLIT_Singular). The pedestrian areas contain a high number of bars and restaurants with tables and chairs outside. The variable PROX_MN_Food may have been chosen because the sounds produced by these activities are noticeable outside, and the perception of the sonic environment can be different in their proximities. The selection of a variable related to singular buildings is interesting. Site 4, where "Castel dell'Ovo" is, has a particular behaviour in relation to the soundscape quality and the LAeq in comparison with other pedestrian areas. The presence of this historical building can make the difference in perception due to its historic richness, beauty or cultural heritage.

Figure 11 shows the relative importance of the variables within the model of the pedestrian areas. The acoustic parameters are all negatively correlated with the soundscape, especially the 5th percentile of loudness (N5) with a $-43.8 \%$ of influence (considered similar to the real perception of the level of noise). The higher the loudness is, the more unpleasant the soundscape is. The noise levels that are exceeded $10 \%$ of the time also have a negative influence on the soundscape perception $(-30.0 \%)$. Roughness and the percentile LA50 are the factors with less influence on the soundscape appraisals. 


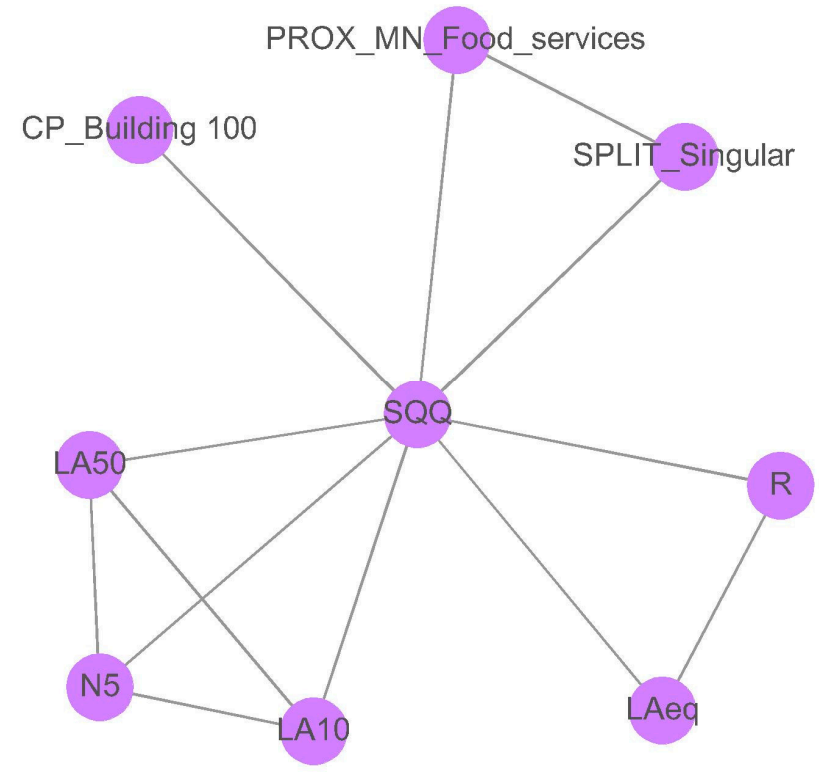

Figure 10. Inferred mRMR network topology of the soundscape quality (SQQ) for the pedestrian areas. The variables selected were "percentage of generic buildings in the aerial photograph within a distance of 100 m" (CP_Building_100), spatial metric "proximity" calculated for the land use "food services" (PROX_MN_Food), spatial metric "split" calculated for the land use "singular buildings" (SPLIT_Singular), sound pressure level exceeded 50\% of time (LA50), A-weighted equivalent sound pressure level (LAeq), roughness (R), loudness(N5) and sound pressure level exceeded 10\% of time.

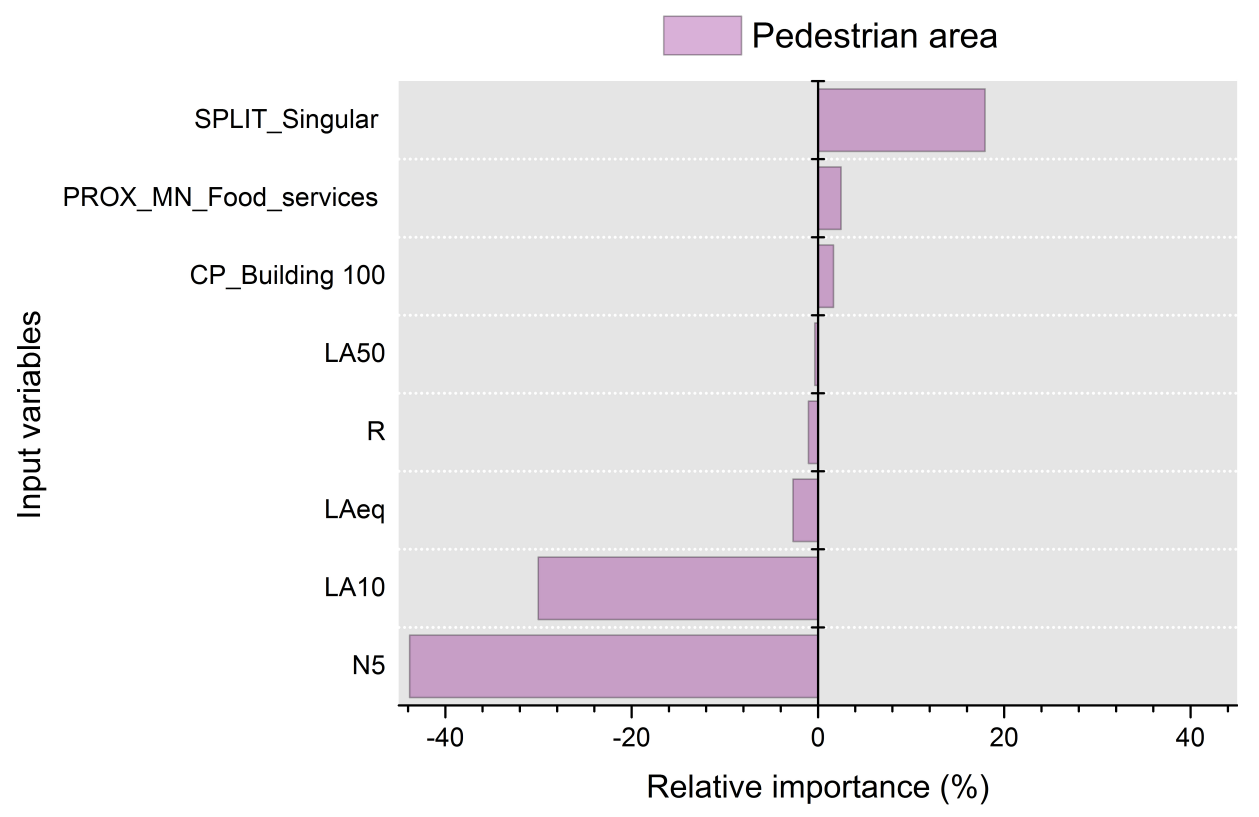

Figure 11. Percentage of relative importance of the predictors on the results calculated with the Olden et al. method for the pedestrian areas. Values higher than zero mean a positive relative effect, and lower than zero, a negative relative effect. The variables selected were spatial metric "split" calculated for the land use "singular buildings" (SPLIT_Singular), spatial metric "proximity" calculated for the land use "food services" (PROX_MN_Food), "percentage of generic buildings in the aerial photograph within a distance of 100 m" (CP_Building_100), sound pressure level exceeded $50 \%$ of time (LA50), roughness (R), and A-weighted equivalent sound pressure level (LAeq), sound pressure level exceeded $10 \%$ of time and loudness (N5). 
Regarding the landscape parameters, SPLIT_Singular also has a positive influence on the perception of soundscape. The fact that there are singular buildings in the perimeter of the interviewee $(175 \mathrm{~m})$ has a high influence on the perception of soundscape $(19.5 \%)$.

\section{Discussion}

The statistical analysis reveals the influence of visual aspects on the sonic environment perception. It is interesting to note that, even if the participants were asked to pay attention to what they were hearing at the moment and the place of the interview, in the road traffic areas, the subjects identified the water as a perceived sound source, and in most cases the interviewers were unable to perceive it. Thus, it seems that there is a strong subjective component on the answer of the interviewees that can be due to the influence of the visual stimuli and expectation on the perception of sounds $[52,53]$.

In the pedestrian areas, since the traffic does not mask other sounds, the variety of predominant sources identified is higher than in other areas. Voices and steps were identified as predominant by a higher percentage of subjects in the pedestrian and limited areas than in the road traffic areas. The predominance of these sources involves the human presence and, therefore, the places where these sources were detected as predominant are preferred to others in terms of stay; users of the waterfront prefer silent places where natural sources are more present than road traffic noise.

In the limited traffic areas and the areas open to road traffic, the traffic noise is able to mask the wanted sounds (like sea sounds), that can be noticed by the subjective component of perception.

The selection of the variables that are included in the model has an important role in its performance. A high number of variables lead to models that are difficult to interpret. Thus, a previous selection of variables is necessary. Usually, this selection is made either according to the correlation between variables or following subjective criteria. Several selection methods choose the top-ranking features, based on mutual information of the variables, without considering the relationships among them. However, these selection methods do not guarantee a good model performance and can lead to a set of highly correlated variables, with the consequent risk of collinearity. In other fields, such as in cancer detection or biology, the use of the mRMR method has been proved to be an efficient way of selecting the variables in order to avoid redundant information. In this case, very good results have been obtained through the application of this method. An approach to the explanation of the soundscape of areas with different traffic conditions was carried out through artificial neural networks. The 'relative importance of the variables' applied to the artificial neural network models give meaning and sense to the results, providing a sign and an amount of contribution to the soundscape quality.

In the limited traffic areas, the LAeq was the only acoustic variable selected by the mRMR. The exclusive selection of this acoustic variable, related to the human hearing range, indicates that other acoustic variables do not add new significant information to the model. The negative relationship between LAeq and the perceived quality of the soundscape has been previously mentioned in different research studies $[17,39,54]$. It is also in agreement with the outcomes of a recent study, in which perceived natural sounds display a negative correlation with LAeq, indicating that natural sounds are masked in areas in which LAeq are typically high [55]. Another recent study supports a positive association between the predominant road traffic and LAeq [56]. Because road traffic is the predominant sound source of the area (see Figure 4), the higher the levels of LAeq are, the most negative the soundscape appraisal is (see Figure 7). The percentages of the sea and the contiguity of the pedestrian areas positively affect the perception of the sonic environment $(33.5 \%$ and $16.9 \%$, respectively). The association with the first factor is due to the positive effects of the natural elements, whereas the association with the second factor can be related to a slight reduction of the noise levels near the pedestrian areas.

In the road traffic areas, only two acoustic parameters were selected by the mRMR algorithms: LA50 and LA95. The relationship of quiet soundscapes and LA50 (that is not affected by single sound events [57]) has been proposed in [13,52], and the importance of this parameter on the perception of quietness has been supported in [58]. LA95 is traditionally the reference parameters for the background 
noise. The high background noise measured in the open to road traffic areas and the nature of the predominant sound source (traffic) explain the negative association of the soundscape quality with LA95. Considering that low background noise is an indicator of quietness [14] in our case, the high values of background traffic noise may denote lack of quietness and therefore, low soundscape quality ratings. The organization of the green areas, the percentage of the sea and the LA50 are the parameters that have the highest association with the soundscape quality $(24.0 \%, 23.9 \%$ and $-21 \%$, respectively). The direction of the association is positive with the spatial parameters and negative with the LA50.

In the pedestrian areas, the number of acoustic parameters selected is greater than for the ones with traffic (limited or open to road traffic streets). As previously mentioned, traffic noise masks other existing sounds in the areas with vehicles, and avoids the clear perception of other sound sources. Since the pedestrian areas have a wider variability of perceived sound sources (see Figure 3), more acoustic parameters (LAeq, R, LA50, LA10, N5) than in the areas with traffic flows are needed in order to characterize and describe the sonic environment. Two acoustic factors have the highest relative importance, N5 and LA10, corresponding to the perceived loudness and the occasional peak events. N5 has been considered in literature a good descriptor of the perceived loudness in cases of eventful sonic areas $[59,60]$. The high anthropogenic activity of the pedestrian areas leads to soundscapes characterized by unsteady sounds that may have contributed to the selection of this parameter as a good descriptor of these areas in the waterfront of Naples. This circumstance is also highlighted by the selection of LA10 (levels of sound that is exceeded the 10 percent of times), that may indicate the unsteady sounds with high sound levels. The third element in order of importance is related to the singular buildings. In fact, the area with the most positive ratings on the soundscape is "Castel dell'Ovo", which is one of the most important historical buildings of the city.

The models express what occurs in the area by means of the variables that compose it, as well as through the variables that have not been selected. For instance, the selection of LAeq only in areas with traffic indicates that other parameters do not add significant information, and that important nuances of the sonic environment were lost due to the road traffic noise masking. The opposite trend was observed in the pedestrian areas, where a wider range of sound sources were perceived.

This paper proposes a methodology to obtain the acoustic and visual factors capable of describing the soundscape of a waterfront. This methodology, however, can be applied to other parts of the city, as well as different cities. The mRMR method was used to select the variables and the ANN to calculate the models for the soundscape perception. The multilayer perceptron neural network is a globally generalizing network which has been proved to be very effective in function approximation, but cannot be easily extended to incorporate prediction limits [61]. Thus, it is not wise to extend the results to other areas, even if they have similar morphological characteristics, but it is possible to extract some tendencies that can help to make decisions in the soundscape design process. Some of these tendencies have been outlined above, such as the positive association of the soundscape appraisal with the percentage of the sea or the organization of the green areas.

These kinds of models are a mathematical reduction of physical and psychological real circumstances. Such reduction always involves loss of information. The variables selected in one area regarding certain data can be different to the variables of a different area, even if both areas have similarities. Thus, it is not possible to expect that considering such number of factor as in this study (101) and restricting the outcomes to the use of 7-9 explanatory variables, the chosen factors were always the same. Future studies should consider different morphological typologies of waterfront in order to evaluate how these may influence the sound perception.

\section{Conclusions}

This work deals with the characterization and comparison of the perceived soundscape quality of three types of area along the Naples waterfront, with reference to the type of traffic, while also considering objective visual and acoustic data. A combined methodology of features selection method, artificial neural network and relative importance of the variables was used. The combination of mRMR, 
ANN and the study of the "relative importance of the variables" made it possible to obtain a coherent interpretation of the behaviour of a particular sonic environment using only the most remarkable objective visual and sonic factors, resulting in a very good performance of the models (in this case-study, the correlation coefficient of the ANN was rLimited_Traffic $=0.96$, rRoad_Traffic $=0.86$, rPedestrian $=0.87$ ).

The application of the methodology used in this study proposes the association of the variables and the soundscape quality. The use of models helps decision-makers to interpret the sonic environment in order to characterize existing scenarios for future intervention $[4,15,33,34]$. Even if a numerical model cannot completely define the sonic environment and any inherent phenomena, it constitutes a powerful approach to its evaluation.

Acknowledgments: The research was funded by the People Programme (Marie Curie Actions) of the European Union's 7th Framework Programme FP7/2007-2013 under REA grant agreement $n^{\circ}$ 290110, SONORUS "Urban Sound Planner".

Author Contributions: Virginia Puyana Romero, Luigi Maffei and Giovanni Brambilla contributed to the original idea and design of the study. Virginia Puyana Romero and Luigi Maffei were responsible for the preparation of the survey. Virginia Puyana Romero was responsible for the measurements as well as the recruitment of the subjects. Giovanni Brambilla and Virginia Puyana Romero were in charge of post-processing the sound measurements. Giuseppe Ciaburro and Virginia Puyana Romero carried out the data analyses. All the authors contributed to the drafting of the manuscript, reading and approving the final version.

Conflicts of Interest: The authors declare no conflicts of interest.

\section{References}

1. European Environment Agency. Good Practice Guide on Quiet Areas. Available online: http://www.eea. europa.eu/publications/good-practice-guide-on-quiet-areas (accessed on 20 July 2016).

2. European Environmental Agency. Noise in Europe 2014. Available online: http://www.eea.europa.eu/ publications/noise-in-europe-2014 (accessed on 20 July 2016).

3. Directive 2002/49/EC of the European Parliament and of the Council Relating to the Assessment and Management of Environmental Noise. Available online: http:/ / eur-lex.europa.eu/legal-content/EN/TXT/ ?uri=celex\%3A32002L0049 (accessed on 20 July 2016).

4. Maffei, L.; Puyana Romero, V.; Brambilla, G.; Di Gabriele, M.; Gallo, V. Characterization of the Soundscape of Urban Waterfronts. In Proceedings of the Forum Acusticum, Krakow, Poland, 7-12 September 2014.

5. Acoustics-Soundscape-Part 1: Definition and Conceptual Framework; ISO 12913-1; International Organization for Standardization: Geneva, Switzerland, 2014.

6. Maffei, L.; Masullo, M.; Aletta, F.; Di Gabriele, M. The influence of visual characteristics of barriers on railway noise perception. Sci. Total Environ. 2013, 445-446, 41-47. [CrossRef] [PubMed]

7. Viollon, S.; Lavandier, C.; Drake, C. Influence of visual setting on sound ratings in an urban environment. Appl. Acoust. 2002, 63, 93-511. [CrossRef]

8. Liu, J.; Kang, J.; Behm, H.; Luo, T. Effects of landscape on soundscape perception: Soundwalks in city parks. Landsc. Urban Plan. 2014, 123, 30-40. [CrossRef]

9. Preis, A.; Hafke-Dyx, H.; Szychowska, M.; Kocinski, J.; Felcyn, J. Audio-visual interaction of environmental noise. Noise Control Eng. J. 2016, 64, 34-43. [CrossRef]

10. Leung, T.M.; Chau, C.K.; Tang, S.K. On the Study of Noise Perceptions Caused by Mixed Noises and Visual Environment. In Proceedings of the 22nd International Congress on Sound and Vibration, Florence, Italy, 12-16 July 2015.

11. Li, H.N.; Chau, C.K.; Tang, S.K. Can surrounding greenery reduce noise annoyance at home? Sci. Total Environ. 2010, 408, 4376-4384. [CrossRef] [PubMed]

12. Jeon, J.Y.; Lee, P.J.; You, J.; Kang, J. Acoustical characteristics of water sounds for soundscape enhancement in urban open spaces. J. Acoust. Soc. Am. 2012, 131, 2101-2109. [CrossRef] [PubMed]

13. De Coensel, B.; Botteldooren, D. The quiet rural soundscape and how to characterize it. Acta Acust. United Acust. 2006, 92, 887-897.

14. Yang, W.; Kang, J. Acoustic comfort evaluation in urban open public spaces. Appl. Acoust. 2005, 66, 211-229. [CrossRef] 
15. Brocolini, L.; Waks, L.; Lavandier, C.; Marquis-Favre, C.; Quoy, M.; Lavandier, M. Comparison between Multiple Linear Regressions and Artificial Neural Networks to Predict Urban Sound Quality. In Proceedings of the 20th International Congress on Acoustics, Sydney, Australia, 23-27 August 2010.

16. Harris, C.M.; Manton, C. Handbook of Acoustical Measurements and Noise Control, 2nd ed.; Mcgraw-Hill: New York, NY, USA, 1991.

17. Brambilla, G.; Gallo, V.; Zambon, G. The soundscape quality in some urban parks in Milan, Italy. Int. J. Environ. Res. Public Health 2013, 10, 2348-2369. [CrossRef] [PubMed]

18. Fastl, H. Audio-Visual Interactions in Loudness Evaluation. In Proceedings of the 18th International Congress on Acoustics, Kyoto, Japan, 4-9 April 2004.

19. Menzel, D.; Faccinelli, E.; Fastl, H. Are absolute thresholds and loudness judgements influenced by different colours. J. Acoust. Soc. Am. 2008, 123, 3162. [CrossRef]

20. Jang, G.S.; Shin, H.; Song, M.J.; Kook, C. The psychological effect of visual and auditory stimuli on the road traffic noise perception. J. Hum. Environ. Syst. 2008, 11, 19-25. [CrossRef]

21. Tokunaga, Y.; Terashima, T.; Ishikawa, A. Influence of Visual Information on Subjective Evaluation of Road Traffic Noise. In Proceedings of the 43rd International Congress on Noise Control Engineering, Melbourne, Australia, 16-19 November 2014.

22. Menzel, D.; Fastl, H.; Graf, R.; Hellbrück, J. Influence of vehicle color on loudness judgments. J. Acoust. Soc. Am. 2008, 123, 2477-2479. [CrossRef] [PubMed]

23. Menzel, D.; Haufe, N.; Fastl, H. Colour-Influences on Loudness Judgements. In Proceedings of the 20th International Congress on Acoustics, Sydney, Australia, 23-27 August 2010.

24. Song, J.; Ma, H.; Yang, Q.; Zhang, S. Interaction of Color Perception and Annoyance Evaluation of Road Traffic Noise. In Proceedings of the 40th International Congress on Noise Control Engineering, Osaka, Japan, 4-7 September 2011.

25. Ma, H.; Nie, W. Influence of Visual Factors on Noise Annoyance Evaluation Caused by Road Traffic Noise in Indoor Environment. In Proceedings of the 43rd International Congress on Noise Control Engineering, Melbourne, Australia, 16-19 November 2014.

26. Farina, A.; Pieretti, N. The soundscape ecology: A new frontier of landscape research and its application to islands and coastal systems. J. Mar. Isl. Cult. 2012, 1, 21-26. [CrossRef]

27. Liu, J.; Kang, J.; Luo, T.; Behm, H.; Coppack, T. Spatiotemporal variability of soundscapes in a multiple functional urban area. Landsc. Urban Plan. 2013, 115, 1-9. [CrossRef]

28. Farina, A. Soundscape and Landscape Ecology. In Soundscape Ecology Principles, Patterns, Methods and Applications; Springer: Dordrecht, The Netherlands, 2014; pp. 1-28.

29. Rey Gozalo, G.; Trujillo Carmona, J.; Barrigón Morillas, J.M.; Vílchez-Gómez, R.; Gómez Escobar, V. Relationship between objective acoustic indices and subjective assessments for the quality of soundscapes. Appl. Acoust. 2015, 97, 1-10. [CrossRef]

30. Brambilla, G.; Maffei, L.; Di Gabriele, M.; Gallo, V. Merging physical parameters and laboratory subjective ratings for the soundscape assessment of urban squares. J. Acoust. Soc. Am. 2013, 134, 782-790. [CrossRef] [PubMed]

31. Botteldooren, D.; Verkeyn, A.; Lercher, P. A fuzzy rule based framework for noise annoyance modeling. J. Acoust. Soc. Am. 2003, 114, 1487-1498. [CrossRef] [PubMed]

32. De Coensel, B.; Botteldooren, D.; Debacq, K.; Nilsson, M.E.; Berglund, B. Clustering Outdoor Soundscapes Using Fuzzy Ants. In Proceedings of the 2008 IEEE World Congress on Computational Intelligence, WCCI 2008, Hong Kong, China, 1-6 June 2008; pp. 1556-1562.

33. Genaro, N.; Torija, A.; Ramos-Ridao, A.; Requena, I.; Ruiz, D.P.; Zamorano, M. A neural network based model for urban noise prediction. J. Acoust. Soc. Am. 2010, 128, 1738-1746. [CrossRef] [PubMed]

34. Yu, L.; Kang, J. Modeling subjective evaluation of soundscape quality in urban open spaces: An artificial neural network approach. J. Acoust. Soc. Am. 2009, 126, 1163-1174. [CrossRef] [PubMed]

35. Lungomare di Napoli: Il Progetto e le Foto Della Riqualificazione. Available online: http://www. napolidavivere.it/2015/09/05/riqualificazione-lungomare-di-napoli/ (accessed on 20 July 2016).

36. Puyana Romero, V.; Brambilla, G.; Di Gabriele, M.; Gallo, V.; Maffei, L. The Influence of the Soundscape on the Tourists' Environmental Quality Perception. In Proceedings of the 10th European Congress and Exposition on Noise Control Engineering, Maastricht, Belgium, 1-3 June 2015. 
37. Mcgarigal, K. Fragstats Help; Department of Environmental Conservation, University of Massachusetts: Amherst, MA, USA, 2014; pp. 1-182.

38. McGarigal, K.; Marks, B. Fragstats—Spatial Analysis Program for Quantifying Landscape Structure; USDA Forest Service: Portland, OR, USA, 1994.

39. Pham, H.M.; Yamaguchi, Y.; Bui, T.Q. A case study on the relation between city planning and urban growth using remote sensing and spatial metrics. Landsc. Urban Plan. 2011, 100, 223-230. [CrossRef]

40. Herold, M.; Goldstein, N.C.; Clarke, K.C. The spatiotemporal form of urban growth: Measurement, analysis and modeling. Remote Sens. Environ. 2003, 86, 286-302. [CrossRef]

41. Puyana Romero, V.; Maffei, L.; Brambilla, G.; Ciaburro, G. Modelling the soundscape quality of urban waterfronts by artificial neural networks. Appl. Acoust. 2016, 111, 121-128. [CrossRef]

42. Mazaris, A.D.; Kallimanis, A.S.; Chatzigianidis, G.; Papadimitriou, K.; Pantis, J.D. Spatiotemporal analysis of an acoustic environment: Interactions between landscape features and sounds. Landsc. Ecol. 2009, 24, 817-831. [CrossRef]

43. Gan, Y.; Luo, T.; Breitung, W.; Kang, J.; Zhang, T. Multi-sensory landscape assessment: The contribution of acoustic perception to landscape evaluation. J. Acoust. Soc. Am. 2014, 136, 3200-3210. [CrossRef] [PubMed]

44. Team, R.D.C. R: A Language and Environment for Statistical Computing; R Foundation for Statistical Computing: Vienna, Austria, 2008.

45. Olden, J.D.; Jackson, D.A. Illuminating the "black box": A randomization approach for understanding variable contributions in artificial neuronal networks. Ecol. Model. 2002, 154, 135-150. [CrossRef]

46. Olden, J. An accurate comparison of methods for quantifying variable importance in artificial neural networks using simulated data. Ecol. Model. 2004, 178, 389-397. [CrossRef]

47. Harrel, F.E.; Lee, K.L.; Mark, D.B. Tutorial in biostatistics multivariable prognostic models: Issues in developing models, evaluating assumptions and adequacy, and measuring and reducing errors. Stat. Med. 1996, 15, 361-387. [CrossRef]

48. De Jay, N.; Papillon-Cavanagh, S.; Olsen, C.; El-Hachem, N.; Bontempi, G.; Haibe-Kains, B. MRMRe: An R package for parallelized mRMR ensemble feature selection. Bioinformatics 2013, 29, 2365-2368. [CrossRef] [PubMed]

49. Axelsson, Ö.; Nilsson, M.E.; Berglund, B. A principal components model of soundscape perception. J. Acoust. Soc. Am. 2010, 128, 2836-2846. [CrossRef] [PubMed]

50. Guastavino, C. The ideal urban soundscape: Investigating the sound quality of French cities. Acta Acust. United Acust. 2006, 92, 945-951.

51. Hong, J.Y.; Jeon, J.Y. Influence of urban contexts on soundscape perceptions: A structural equation modeling approach. Landsc. Urban Plan. 2015, 141, 78-87. [CrossRef]

52. Brambilla, G.; Maffei, L. Responses to noise in urban parks and in rural quiet areas. Acta Acust. United Acust. 2006, 92, 881-886.

53. Bruce, N.S. The effects of expectation on the perception of soundscapes. Appl. Acoust. 2011, 85, 1-11. [CrossRef]

54. Nilsson, M.E.; Botteldooren, D.; De Coensel, B. Acoustic Indicators of Soundscape Quality and Noise Annoyance in Outdoor Urban Areas. In Proceedings of the 19th International Congress on Acoustics, Madrid, Spain, 2-7 September 2007.

55. Hong, J.Y.; Jeon, J.Y. Soundscape Mapping in Urban Contexts Using GIS Techniques. In Proceedings of the 43rd International Congress on Noise Engineering, Melbourne, Australia, 16-19 November 2014.

56. Kim, S.; Hong, J.Y.; Jeon, J.Y. Landscape Factors Affecting Soundscape in Urban Environments. In Proceedings of the 22nd International Congress on Sound and Vibration, Florence, Italy, 12-16 July 2015.

57. Botteldooren, D.; De Coensel, B. Quality Labels for the Quiet Rural Soundscape. In Proceedings of the Inter Noise 2006, Honolulu, HI, USA, 3-6 December 2006.

58. Aletta, F.; Margaritis, E.; Filipan, K.; Puyana Romero, V.; Axelsson, O.; Kang, J. Characterization of the Soundscape in Valley Gardens, Brighton, by a Sound Walk Prior to an Urban Design Intervention. In Proceedings of the Euronoise 2015, Maastricht, The Netherlands, 31 May-3 June 2015; pp. 1547-1552.

59. Fastl, H.; Zwicker, E. Psycho-Acoustics: Facts and Models; Huang, T.S., Kohonen, T., Schroeder, M.R., Eds.; Springer Series in Information Sciences; Springer: Heidelberg, Germany, 2007. 
60. Genuit, K.; Fiebig, A. The Acoustic Description of Patterns in Soundscape. In Proceedings of the Inter-Noise 2007, Istanbul, Turkey, 28-31 August 2007.

61. Mcguire, S.; Basner, M.; June, M. Predictions of Sleep Disturbance for Different Nighttime Airport Operation Strategies Using a New Markov State Transition Sleep Model. In Proceedings of the Euronoise 2015, Maastricht, The Netherlands, 31 May-3 June 2015; pp. 1281-1284.

(c) 2016 by the authors; licensee MDPI, Basel, Switzerland. This article is an open access article distributed under the terms and conditions of the Creative Commons Attribution (CC-BY) license (http:/ / creativecommons.org/licenses/by/4.0/). 